\title{
Exploring Providers' Perception Towards Provision of Sexual and Reproductive Health Services for Unmarried Adolescents in Gamo Zone, Southern Ethiopia: A Phenomenological Study
}

\author{
Nigussie Boti Sidamo $\mathbb{D}^{1-3}$ \\ Kassa Daka Gidebo' \\ Yohannes Dibaba Wado ${ }^{4}$ \\ Amene Abebe (D) \\ Mengistu Meskele (D) \\ 'Department of Public Health, College of \\ Medicine and Health Sciences, Wolaita \\ Sodo University, Wolaita Sodo, Ethiopia; \\ ${ }^{2}$ Department of Reproductive Health, \\ College of Medicine and Health Sciences, \\ Arba Minch University, Arba Minch, \\ Ethiopia; ${ }^{3}$ Department of Public Health, \\ PHARMA College Wolaita Sodo Campus, \\ Wolaita Sodo, Ethiopia; ${ }^{4}$ African \\ Populations and Health Research Center, \\ Nairobi, Kenya
}

Background: Healthcare providers play a critical role in the provision of sexual and reproductive health services for adolescents. In Ethiopia, due to different reasons, including healthcare providers associated reasons, most unmarried adolescents are not accessing the services. However, little is known about healthcare providers' perception towards the provision of SRH services for unmarried adolescents. This study aimed to explore healthcare provider perception towards the provision of SRH services to unmarried adolescents in Gamo zone, Southern Ethiopia.

Methods: A qualitative phenomenological research design was used in May 2021. Fifteen healthcare providers (HCPs) working in adolescent and youth sexual and reproductive health centers were involved in this study. A purposive sampling technique was used to select healthcare providers assuming they are "information-rich" regarding the phenomenon of interest. Inclusion of the study participants was continued until data saturation is reached. To analyze the data, we used inductive thematic analysis, method, and main themes, which captured the diverse views and feelings of the participants. To maintain the trustworthiness of the data, we used dependability, transferability, conformability, and credibility.

Results: In this study, individual-level attributes such as healthcare provider's personal belief, attitude, and motivation; community-level influences like socio-cultural norms, religious reasons, and lack of parental support; and health system setbacks like shortage of essential medical supplies and lack of training are identified as major obstacles in the provision of sexual and reproductive health services for unmarried adolescents.

Conclusion: Provision of sexual and reproductive health services for unmarried adolescents is constrained by the interplay of factors acting at an individual level, community level, and health system level. The Ministry of Health $(\mathrm{MOH})$, program planners and policymakers are recommended to give due attention to fulfill the necessary inputs, improving healthcare provider's attitude and skill and engagement of religious and community leaders to create a safe and supportive environment for providing sexual and reproductive health services to unmarried adolescents.

Keywords: healthcare provider, perception, sexual and reproductive health services, unmarried adolescents, Gamo Zone, Southern Ethiopia

\section{Introduction}

Globally, substantial efforts were made to promote sexual and reproductive health (SRH) service uptake of adolescents. However, it is still a big problem in many countries, particularly in sub-Saharan Africa, including Ethiopia. ${ }^{1}$ Due to a lack of
Correspondence: Nigussie Boti Sidamo: Mengistu Meskele Email Hanehalid@gmail.com; mengistu77@gmail.com 
comprehensive knowledge of SRH problems, most adolescents do not have the information or means to protect themselves from these problems. More than one-fourth of girls in sub-saharan Africa (SSA) can not access family planning services, making them more vulnerable to unplanned pregnancies and spreading of HIV and other sexually transmitted diseases. For example, worldwide, 1.65 million adolescents are living with HIV, with 21 million adolescents becoming pregnant, 12 million girls giving birth, 5.6 million pregnancies which end in abortion (among which 3.9 million end in unsafe abortion), there is a high rate of early marriage, nearly one in 20 adolescents are believed to contract a STI each year, and a high proportion of stillbirth and newborn deaths as well as maternal deaths occur each year. ${ }^{2-4}$ Evidence shows that making SRH services available, accessible, appropriate, and adequate in addressing the SRH needs of adolescents plays an important role in averting sexual and reproductive health problems. ${ }^{1,5-7}$

Despite the global and national commitments to adolescents' SRH needs, the provision of the service remains highly inadequate, especially in low- and middle-income countries (LMICs). ${ }^{8}$ In SSA countries, the utilization of SRH services by adolescents is very minimal. ${ }^{9,10}$ For instance, in a study conducted in Rwanda, healthcarerelated barriers such as lack of privacy, high costs for the services, as well as lack of comfortable separated rooms were reported as the barriers of SRH services. ${ }^{11}$ Another study conducted in Nigeria shows individual, social, and health system barriers were reported as barriers of adolescents of accessing SRH information and services. ${ }^{5}$ Another similar study conducted in Kenya also shows negative health workers' attitudes, distance to the health facility, unaffordable cost of services, negative social-cultural influences, lack of privacy, and confidentiality of information are identified as major barriers of accessing SRH services and information. ${ }^{12}$

In Ethiopia, adolescents suffer from sexual reproductive health problems like STIs/HIV infection, early marriage, and unwanted pregnancies. ${ }^{13,14}$ Ethiopia has one of the highest adolescent fertility rates in Sub-Saharan Africa. $^{3}$ The government of Ethiopia, like many other SSA countries, is committed to achieving universal access to reproductive health, including access to safe, affordable, and effective methods of contraception. ${ }^{15}$ However, access to sexual and reproductive health services by adolescents is still continuing to be a public health concern. ${ }^{16}$ With the National Adolescent Reproductive Health
Strategy, the government of Ethiopia has prioritized adolescents' SRH to invest more resources and expand access to sexual and reproductive health services for adolescents through the Ethiopian health extension workers' scheme. ${ }^{17}$ In Ethiopia, sexual and reproductive health services for adolescents are commonly provided through two service delivery models: youth centers and integrated health services. Youth centers only serve adolescents and can either be facility-based or community-based, while in the integrated health services model adolescents receive services within the general health system together with the general public. The services are provided in public and NGO healthcare facilities, youth centers, and schools. At each adolescents youth sexual and reproductive health center there are two trained healthcare providers assigned. ${ }^{9}$

Despite these positive efforts of the Ethiopian government, provision of SRH services for unmarried adolescents (10-19 years) remains an unresolved public health challenge. Limited evidence in Ethiopia shows most Ethiopian adolescents often face challenges in accessing SRH services such as contraception and safe abortion services, HIV and other sexually transmitted infections testing and care services, and sexual violence services due to numerous barriers. ${ }^{3,18,19}$

Healthcare providers are critical to providing quality sexual and reproductive health services for adolescents, which is why it is essential to consider their attitudes and perception towards services provided to adolescents. Previous studies reveal that healthcare workers' negative attitudes towards adolescents, lack of respect for adolescents' privacy, and a lack of skills necessary for providing services to adolescents are contributing factors for poor access to sexual and reproductive health services for adolescents. ${ }^{4}$ In addition, poor providers' competence, unsupportive environment, perceived lack of information and attitude towards SRHs, poor implementation, and lack of multi-sectoral engagement are major barriers to adolescents use of SRH services. ${ }^{3}$ Another study showed social values, and community attitude, the inappropriate package services, negative attitudes of providers towards unmarried adolescents, limited SRH knowledge, and lack of open discussion of sexual matters were mentioned as barriers to accessing services among adolescents' in Ethiopia. ${ }^{19}$

Increasing the number of health facilities that provide SRH for adolescents might not be enough to ensure quality care services. In addition, the perception of healthcare providers towards sexual and reproductive health services 
provided for adolescents has a direct impact on access to services, quality, and utilization of quality services. But, in Ethiopia, there is no sufficient evidence with regard to healthcare providers perception towards provision of SRH services for unmarried adolescents. Therefore, this study aimed to explore and gain an in-depth understanding of healthcare providers' perception towards the provision of SRH services to unmarried adolescents in Gamo Zone, Southern Ethiopia.

\section{Methods}

\section{Study Area}

This study was conducted in Gamo Zone, Southern Ethiopia. The zone is found under the southern nation, nationalities and peoples (SNNP) regional state and divided into 18 districts (14 rural and four town administration). Gamo Zone is bordered by Wolaita, Dawro, and Gofa Zones in the north, Lake Abaya in the northeast, Amaro special woreda and Dirashe special woreda in the southeast, and South Omo in the southwest. The administrative center of Gamo Zone is Arba Minch town. The town is located $450 \mathrm{~km}$ from Addis Ababa, the capital city of Ethiopia. Arba Minch is located at an altitude of 130 above sea level with an average temperature of $29^{\circ} \mathrm{C}$. According to a 2021 year Zonal health department report in Gamo Zone there are six hospitals (one general and five primary hospitals), 56 health centers, and 302 health posts; they provide preventive, curative, and rehabilitative care.

\section{Study Design}

We used a qualitative phenomenological research approach to explore healthcare providers' perception towards the provision of sexual and reproductive health services for unmarried adolescents in Gamo Zone, Southern Ethiopia. This may enable a detailed description of what is happening in the actual context and a deeper understanding of the background procedures that come into play.

\section{Eligible Population}

The target study population for this study were healthcare providers working in adolescent and youth health centers in selected healthcare facilities.

\section{Selection of Study Sites and Health Facilities}

We selected purposively three districts (Arba Minch town, Arba Minch Zuria district, and Gacho baba districts). In
Arba Minch town, there are two health centers, two youth friendly centers, one NGO center, one primary hospital, and one general hospital. In the Arba Minch Zuria districts, there are four health centers. In the Gacho baba districts, there are four health centers. However, adolescent and youth sexual and reproductive health centers were select based on the services available and ensuring the different types of model (health facility, NGO center, or youth center). In the selected three district there are seven health centers offering integrated SRH services, one NGO center, and two youth friendly centers which were providing SRH services, and all of them were included for this study.

\section{Selection of Healthcare Providers}

This study was conducted among healthcare providers (HCPs) working in adolescent and youth sexual and reproductive health centers. The purposive sampling technique was used to select healthcare providers by assuming the HCPs "information-rich" respondents had extensive knowledge about a particular behavior, experience, or phenomenon of interest. ${ }^{20}$ We selected HCPs by taking the following consideration: their firsthand experience, they should have experience of at least 6 months in providing SRH services to adolescents, and willingness to participate in the study. HCPs should currently work in selected adolescent-friendly health service centers. The study participants were invited until data saturation was achieved. To determine data saturation we conduct interviews until we reached the point of no new information; no new themes; no new coding; and the ability to replicate the study as recommended by O'Reilly and Parker. ${ }^{21}$ Also, at the same time, a sample size should be large enough to sufficiently describe the phenomenon of interest and address the research question at hand. In doing this, we conducted 15 key informant interviews. All the key informant interviews were tape-recorded and notes were also taken to guarantee the accuracy of the data.

\section{Definition of Terms}

Healthcare providers are those individuals who provide preventive, curative, promotional, or rehabilitative healthcare services in a systematic way to people, families, or communities. $^{9,22}$ In this study this applies to those who are involved in history taking, physical examination, and treatment and counseling of sexual and reproductive health issues at the healthcare facilities. 


\section{Data Collection methods}

An interview guide was developed after reviewing relevant literature. ${ }^{3,4,11,23}$ The English version was translated to the local language Amharic, for data collection. The interview guide was reviewed by all authors and refinement has been done accordingly. Before the actual data collection, the developed interview guide was pretested by four participants who were not included in this particular study. Based on the inputs from the pretest, the interview guide was revised for actual data collection. Data collection was carried out by the principal investigator and two experienced trained research assistants. Key informant interviews with healthcare providers were held through face-to-face interviews by using the Amharic language to reduce bias and errors. The interviews were conducted at the participants' respective workplaces to maintain privacy as well as convenience. During interviews probing questions were asked to participants to explore the issues indepth. All interview information was tape-recorded after receiving consent from each participant. We followed the current COVID-19 pandemic measures and considered the use of personal protective materials and physical distancing.

\section{Data Processing and Analysis}

The audio recorded interview data were first transcribed verbatim in Amharic language. Then the transcribed data were translated into English. The translated data were cross-checked with the audio file to ensure its proper transcription and translation. The principal investigator read the translated data repeatedly to understand the concept and related meanings of the data. To analyze the data, we used inductive thematic analysis, which aimed to identify a set of main themes which captured the diverse views and feelings expressed by participants. Thematic analysis is useful for summarizing key features of a large data set, as it forces the researcher to take a well-structured approach to handling data, helping to produce a clear and organized final report. ${ }^{24}$ The principal investigator carried out coding, categorizing, and theming. Key themes and sub-themes were checked and verified by the other investigators and common categories and themes wer agreed. To identify themes and subthemes we read and re-read line by line and listened to the recordings to match a sense of what had been said by each study participant. Both theme and subtheme were induced from the text itself through repeated reading. A statement was grouped by code to the corresponding theme. Once a theme was established, the transcripts were re-read to ensure the themes appropriately reflected the content of the data. All themes identified were checked to reflect the contents of discussions from the KIIs. Finally, thematic analysis was conducted to identify major themes that helped to answer the research question. Participants' direct quotations were used to elaborate the emergent themes. To facilitate the data analysis we used Open Code version 4.03 software for data analysis.

\section{Trustworthiness}

To maintain credibility, we used KII guides which were evaluated by experts from Arba Minch University department of Reproductive health. The data collection tool (interview guide) was pre-tested on four participants before actual data collection. To diversify the study participants, the key informants were recruited based on age, sex, and work experience to get a broader range of viewpoints from different participants. Furthermore, the data collection assistant and principal investigator knew the local language fluently. This is important to reduce the possibility of misunderstanding during the study and ensured the credibility of the findings. To maintain dependability, we shared the transcription and translation with the key-informant participants. Then, they provided their comments and consensus was made on some vague ideas. To maintain transferability of the overall research process, the study setting, and study participant characteristics were well stated in the methodology part. During data collection, probing interview techniques were used between each question, which involved asking further questions to in-depth understand their perception. The data collectors used a tape-recorder and written field notes to record the interviews. Finally, the thick description was completed. To maintain conformability, all data collected from the fieldwork were kept and were frequently consulted, discussed, and agreed upon between the investigators during the analysis and interpretation phase that ensured the conformability of the findings. The study instruments were translated into local languages and the inquiry was conducted in the language of the participant's choice to reduce bias and errors.

Also, the principal investigator as well as other research team members have good experience in qualitative research. This experience and specialization were essential in order to address the research question appropriately. The context of this study setting was different from the setting in which principal investigators have been 
working and living. The KII participants were not familiar with the principal investigator. In order to minimize researcher bias, the principal investigator tried to set aside their assumptions, perceptions, and values, and prior knowledge during data collection, coding, and analysis. But, we are not overconfident while interpreting the findings, and attention was taken to balance interpretation with direct quotations from the study participants. The other technique was peer debriefing, performed by the qualitative expert of Arba Minch University department of Reproductive health staff, mainly focused on qualitative data coding and analysis. The last technique was prolonged engagement. The prolonged engagement was achieved by staying in the study area for a long time. During this time the principal investigator confirmed the points rose in the KIIs. He observed and confirmed different issues.

\section{Results}

\section{Participant Profile}

The key informants' interviews were conducted with a total of 15 respondents. Five of the key informants were females and ten were males. With regards to their profession, nine of them had a bachelor of science (BSc) degree in Health Officer (HO), whereas four of them had a BSc degree in Nursing. Two of them had a Masters in public health. Their ages ranged between 25 and 45 years. All of them had more than 2 years of working experience. The interviews lasted on average 35 minutes.

\section{Themes and Subthemes}

Based on major findings from qualitative data, the researchers grouped it thematically into four major themes; individual barriers, societal barriers, health system barriers, and perceived solutions to improve SRH services for unmarried adolescents. The emerged themes are presented according to the main themes and subthemes in Table 1.

\section{Theme I: Individual-Level Barriers That Influence the Provision of SRH Service for Unmarried Adolescents}

Individual-level barriers that limit the provision of sexual and reproductive health services for unmarried adolescents include healthcare provider personal belief, healthcare provider attitude, and healthcare provider motivation to provide SRH services for unmarried adolescents.
Table I Themes and Subthemes

\begin{tabular}{|l|l|}
\hline Themes & Subthemes \\
\hline Individual barriers & $\begin{array}{l}\text { Healthcare providers personal } \\
\text { beliefs }\end{array}$ \\
\cline { 2 - 2 } & Healthcare provider attitude \\
\cline { 2 - 2 } & Healthcare provider motivation \\
\hline Community barriers & Socio-cultural norms \\
\cline { 2 - 2 } & Religious belief \\
\cline { 2 - 2 } & Lack of parental support \\
\hline \multirow{3}{*}{ Health system barriers } & $\begin{array}{l}\text { Shortage of essential medical } \\
\text { supplies }\end{array}$ \\
\cline { 2 - 2 } & Lack of training \\
\hline \multirow{4}{*}{$\begin{array}{l}\text { Perceived solution to improve provision of sexual and } \\
\text { reproductive health services } \\
\text { for unmarried adolescents }\end{array}$} & $\begin{array}{l}\text { Strengthen private institutions } \\
\text { program in the community }\end{array}$ \\
\cline { 2 - 2 } & $\begin{array}{l}\text { Strengthen the current youth } \\
\text { friendly center }\end{array}$ \\
\cline { 2 - 2 } & $\begin{array}{l}\text { Engage religious leaders in the } \\
\text { provision of sexual and } \\
\text { reproductive health services }\end{array}$ \\
\hline
\end{tabular}

\section{Subtheme: Healthcare Provider Personal Beliefs}

Under this subtheme, most of the key informants believed that providing SRH services for adolescents would lead them to promiscuity, and adolescents must abstain from any sexual activities before marriage. They perceived that providing sexual and reproductive health services for unmarried adolescents means that the health worker is encouraging unmarried adolescents to do a sexual activity before marriage. Healthcare workers were seen as having an essential role in protecting the adolescent herself as well as avoiding the spread of premarital sex in the community.

One of the healthcare providers said:

I advise my children and as well as other adolescents to abstain from doing premarital sex because I do not support premarital sex. I teach young people not to do this (premarital sex); I tell them to take care of themselves as much as possible. So I encourage young people to abstain because the best option is to abstain from any sexual activity. (45 years old male, key informant).

Another participant also said: 
... I advise the adolescents to be abstinence from doing sex before marriage. Which I recommend for my children as well as young people who come to me for advice. (29 years old female, key informant).

However, a few healthcare providers believed that the provision of SRH services should be beyond counseling about abstinence.

... as a human being, no one can say don't do sexual intercourse, because it is natural biological processes ... But what we all need to do is educating adolescents to understand the consequences of premarital sex and inform them to make it safe as possible. (28 years old male, key informant).

Even if we teach the adolescents to abstain from premarital sex; maybe a few of the adolescents may accept the ideas. Rather than saying to adolescents not do premarital sexual intercourse; it is better to pay attention to counseling the adolescent about the consequence and available options of SRH services because adolescents like another human being they have physiological and biological need. (27 years old female, key informant).

\section{Subtheme: Healthcare Provider Attitude Towards Provision of SRH Services}

Under this subtheme, most healthcare providers described ambivalent attitudes to provide sexual and reproductive health services for unmarried adolescents regarding commonly safe abortion and contraceptive services. For further understanding, lets see what participants said:

For me, this thing (doing safe abortion) is tough!! (35 years old male, key informant).

I do not provide safe abortion services. (45 years old male, key informant).

If someone asks me for safe Abortion service after doing unsafe sex, I will not provide it (safe abortion service). (31 years old male, key informant).

One of the study participants who works in a youthfriendly center said:

... If a 12-year-old girl came and told me she needed family planning services. I will advise her to be abstinence. So I would not give her family planning. (30 years old female, key informant).

However, few healthcare providers will give any sexual and reproductive health services for adolescents, even their sisters or relatives.
Of course, I will provide for those all adolescents who come to seek services even 10 or 12 years old; I will give the service as they want. (37 years old male, key informant).

The response from these respondents implied that the healthcare providers did not provide SRH services for unmarried adolescents due to their personal beliefs and attitude. However, to provide services for adolescents in the best way, the healthcare provider should put aside their personal beliefs and attitudes. In reply to this stem, respondents gave their opinion in the following way:

... It (individual feeling) can have an impact on service delivery. But I should not allow my personal beliefs to dominate the service delivery for adolescents. I have to provide the services based on the need of the coming customers. (45 years old male, key informant).

I hate the action (doing premarital sex)!! As long as it is not my position. But as long as I am her counselor, I should not speak offensive words or I don't show unnecessary behaviours. (25 years old female, key informant).

The healthcare providers working in adolescents and youth centers also believe that they ought to distance themselves from their personal and moral beliefs to respond best to adolescents' needs.

One of the participants said:

As a professional, I should provide the service for any adolescents, even for my sister herself as long as she says I want the service. But, what should we do, must first teach everything. Then we have to provide the service as they want. (30 years old male, key informant).

\section{Subtheme: Healthcare Provider Motivation to Provide Services}

Concerning the future life of adolescents, the complication of the health problems adolescents experience and the personal satisfaction from the service provision was mentioned by most study informants as a motivating factor to provide the SRH services for adolescents.

One of the key informant interview participants explained:

As a member of the community, I have tasted the guilt. When you see such a complex condition, you think that what I shall do if it happened to me, what I shall do if it happens to my sister. I will be motivated when you see those who adolescent after their problems is solved by you. (30 years old male, key informant). 
Another key informant also explained:

Because I know the following risk if I do not provide the service. Unless I provide service for the adolescents who come in to seek services, they will either kill themselves or get into unwanted trouble. So, I personally safe the life of these kinds of adolescents by providing the services. (29 years old female, key informant).

Furthermore, participant 3 stressed the idea and put his opinion as follows:

When you see adolescents between the ages of 15 and 16 years come for safe abortion, you will get shocking have you imagine how difficult life is! They become pregnant by this age ... I am happy when I help those adolescents who are in such a difficult situation. (37 years old male, key informant).

Healthcare providers are demotivated to provide SRH service for an unmarried adolescent when the adolescent repeatedly asks them for the same services.

Some young people come repeatedly and asked for the same services over and over again. When you look at them, you have something to think about, both religiously and culturally. (37 years old male, key informant).

Most study participants also described that they were demotivated due to when the adolescents show misbehavior. They highlighted it as one of the critical challenges to provide sexual and reproductive health services for adolescents.

... the critical challenges to provide sexual and reproductive health services are adolescent misbehavior. Even the healthcare providers volunteer to provide health education for adolescents, the adolescents say, "We do not need health education." As a result, healthcare providers do not have the dare to do it as professional. (28 years old female, key informant).

One of the study participants who worked in a youthfriendly center said:

... When I asked them to give me just five minutes to teach ... most of them said that we came from school. We came here for a break. We don't need health education, what does it do? Even they were joking about the healthcare provider. They mock, saying, "There is no condom". (25 years old female, key informant).

\section{Theme 2: Community-Level Barriers That Influence the Provision of SRH Service for Unmarried Adolescents}

Under this main theme social-cultural norm, religious beliefs, and lack of parental support inhibited the provision of sexual and reproductive health services for unmarried adolescents:

\section{Subtheme: Socio-Cultural Norms}

Most healthcare providers describe that due to the socialcultural norm of the community they did not give SRH services for unmarried adolescents. They suggested that social norms in Ethiopia are strong; the adolescents may face different problems if they utilized sexual and reproductive health services. In their community, their culture does not allow them to get services. Most adolescents usually come to their facility for sexual and reproductive health services after they develop a sexual and reproductive health problem. In reply to this stem, respondents gave their opinion in the following way:

For example, if someone sees the adolescents around the area where family planning or abortion is given, the adolescent girl can face punishment from her family member. Because there is a perception in society that adolescents should start use family planning after they got married. (31 years old male, key informant).

Most study participants perceived that sexual intercourse and contraceptive use among unmarried adolescents is culturally unacceptable. Similarly, various healthcare providers advocate for total sexual abstinence among unmarried people and view pre-marital sexual intercourse as immoral. In reply to this stem, one respondent gave their opinion in the following way:

A girl's use of family planning means that she begins premarital sex. Even for such young people, the community is being dishonored and they believe that they may teach other children such unethical behavior. This is the most discouraging action especially for young adolescents. (35 years old male, key informant).

\section{Subtheme: Lack of Parental Support}

The majority of study participants mentioned that parental negative perceptions towards adolescents receiving sex education and information and services is one of the barriers to provide sexual and reproductive health services for unmarried adolescents. This negative perception is 
associated with cultural norms, even discussing SRH issues with unmarried adolescents is a cultural taboo. Moreover, they believe that discussing or educating unmarried adolescents about SRH issues will motivate the children to engage in premarital sex. Premarital sex is a socially unacceptable practice.

With regards to child parenting what is imprinted in our society is that when you discuss with adolescents about SRH issues or what seems to be important, they think adolescents will be ruined tomorrow or they believe that tomorrow's life of adolescents will fall into something bad. (26 years old male, key informant).

The majority of study participants describe that lack of parental support is a great challenge for healthcare providers to provide SRH services for unmarried adolescents. Especially providing community-based education related to reproductive health services for unmarried adolescents is difficult to them; due to this reason they did not provide community-based education.

One of the female participants said:

Parents will not allow the healthcare providers to educate their adolescents about sexual and reproductive health issues. They think that you have come to corrupt their children (adolescents). (28 years old male, key informant).

Another participant also stated that

... Parents believed that it (sexual and reproductive health services) does not consider our cultural norms and values. It violated community norms and religious practices. Discussing the sexual-related issue with the children may motivate them to engage in premarital sex. Premarital sex is a socially unacceptable practice. Due to this reason, most healthcare providers do not give any communitybased sexual and reproductive health-related education for unmarried adolescents and the local communities are not interested to send their children for education. (25 years old female, key informant).

One of the study participants also shared her experiences and said:

I will not allow anyone to come and teach my daughter about sexual and reproductive health services. (28 years old female, key informant).

\section{Subtheme: Religious Beliefs}

The healthcare providers admitted that religious beliefs had an impact on the provision of sexual and reproductive health services for unmarried adolescents. Furthermore, healthcare workers report that the provision of safe abortion services for adolescents was against their religious rules.

For further explanation, respondents 1 and 10 gave their opinion as follow:

It (my religion) influences my service provision. For instance, I do not provide safe abortion services, but I will refer them to the place where the services are provided as long as the young people come looking for service. (45 years old male, key informant).

For me, this thing (doing safe abortion) is very difficult!! (Taken as doing sin). Even though people are different in their beliefs, it is not the man who creates man, but God. Even though I was created by man, abortion is the termination of life. (31 years old male, key informant).

Furthermore, participant 5 stressed the idea and put her opinion as:

According to my religion, if there is anything that is not allowed in my religion, I will leave my job and I will not do it. For example, if anyone wants a safe abortion service, I will not do it because my religion does not allow me to do it. Also, it is not my position. So if someone asks me for a safe abortion service after doing unsafe sex, I will not provide it (safe abortion service). (25 years old female, key informant).

\section{Theme 3: Health System Barriers}

This main theme is the one that study respondents give enfaces. The majority of respondents suggested that the main barriers in providing adolescent-friendly SRH services. This theme has two subthemes, namely: a shortage of essential medical supply and lack of training.

\section{Subtheme: Shortage of Essential Medical Supplies}

The majority of study participants mention that a shortage of medical supplies and equipment like modern contraceptive methods, condoms, and test kits (pregnancy and STI kits) limit the sexual and reproductive health services for unmarried adolescents. That equipment was critical for the provision of the services. Health workers narrated that they could not provide SRH services due to inadequate medical supplies. For further understanding, lets see what the respondents said:

Shortage of input, especially nowadays. For instance, in our facility, there are no family planning methods like 
condoms and emergency contraceptive methods. Also, there is no equipment to test the adolescent. For example, we do not have an HIV test kit, we do not have a pregnancy test kit ... so, we do not counsel them (adolescents) and we also do not dare to teach because we don't have resources ... How do I do it without equipment? (26 years old female, key informant).

Another participant also said:

... most adolescents come and ask for condoms, but we don't have a condom, we are out of stock. We have repeatedly asked the concerned bodies, but have not received a response. (25 years old female, key informant).

\section{Subtheme: Lack of Training}

According to the interviewed healthcare providers, lack of training on sexual and reproductive health services significantly challenged the provision of services for adolescents. They also highlighted that the lack of training limited them to provide quality healthcare services for adolescents. One healthcare provider who works in a youth-friendly center said that they did not provide longacting family planning for adolescents.

One female study participant who works in a youth center said:

I do not provide all family planning services like Implant and IUCD for young people because training is required to provide these types of family services. (28 years old male, key informant).

\section{Weak Institutional Support}

Most respondents describe that weak institutional support for adolescents-youth-friendly centers constrains service provision to adolescents. This is reflected in unfriendly facility settings and lack of necessary equipment and edutainment materials that will attract adolescents to the facility. This unfriendly facility setting may discourage adolescents who require these services. As a country, Ethiopia's sexual and reproductive health is not a well-established sector.

For further explanation, lets see what the respondent said:

Everyone has a role to play in youth health. But the main stakeholder goes to the government. Because it is not easy to provide services. It starts with the construction of facilities. A lot of things are needed. Therefore, I say the government should expand the focus on what is being arrested because the youth problem is a national problem and if we use it properly and use the resources we have properly, they will also be a threat to our country. (35 years old male, key informant).

Another respondent also said that lack of essential equipment and educational materials is one of the key barriers to provide services that need an urgent response from responsible bodies.

... The government should pay close attention to the training for the professionals, since the healthcare providers should be adequately qualified. This is something that can change access to services for a young person, especially when the professional is qualified, they will provide quality services. (29 years old male, key informant).

Adolescents will not come again to the center once they don't get what they asked, and they often do not come. (27 years old male, key informant).

\section{Theme 4: Perceived Solution to Improve the Provision of SRH Services for Unmarried Adolescents}

Most of the participants suggested that to improve the provision of SRH services for unmarried adolescents, the governmental bodies should give due attention to adolescents and strengthen awareness creation programs in the community. Furthermore, they should support the current youth-friendly center, and they also should involve religious leaders in the provision of SRH services for unmarried adolescents.

\section{Subthemes: Strengthen Private Institutions}

Most of the participants suggested that to improve access and utilization of sexual and reproductive health services for unmarried adolescents strengthened services provision in the private institution is crucial: For further understanding, lets see what the participants said:

Most of the time, the adolescents go to private institutions for services because in the government institutions most of the time the adolescents may not get the service adequately. (45 years old male, key informant).

There are probably a lot of clients who need sexual and reproductive health services at public health facilities. Adolescents want to hide they go to private facilities. Also, there is a lot of professional turnover in government institutions. Once they are assigned in a youth-friendly center, they will rotate into another place. (35 years old male, key informant). 
Most of the respondents from government institutions also confirmed that

The flow of adolescents is not good enough. As you know the provision of SRH Services needs privacy. Even we provide SRH services by keeping their privacy; they will go to private institutions. (31 years old male, key informant).

Another respondent from private institutions also confirmed that

The adolescents may experience unwanted pregnancies due to a variety of reasons. They come here (a private institution) as a preference for that (safe abortion) service. (37 years old male, key informant).

\section{Subthemes: Strengthen Awareness Creation Programs in Our Community}

Most healthcare providers describe that the main barrier for adolescents to access SRH services is related to social level factors. So the respective body should strengthen community-based awareness creation programs to reduce stigma and discrimination, to improve parental as well as community support for adolescents.

... the negligence of the community makes adolescents vulnerable to various reproductive health-related diseases. I think the other is the negligence of the adolescents themselves. Currently, adolescents do not go in the way of their mother or father and the community. The other may be related to family control. The more family control, the worse the problems for adolescents. (25 years old female, key informant)

Therefore, I believe series of awareness-raising activities are needed in our community. (35 years old male, key informant).

There should be awareness creation programs in our community related to sexual and reproductive health. (30 years old male, key informant).

\section{Subtheme: Strengthen the Current Youth Friendly Center}

Study participants suggested that family involvement should be strengthened around youth-friendly health services to make all kinds of services accessible for adolescents. Furthermore, they said:

If we want to provide complete services to the adolescents, the services that the youth center provides must also involve the parents of the adolescents. At least every 6 months there should be a meeting with parents of the adolescents to create awareness about sexual and reproductive health issues and to encourage their adolescents in getting services. Simply establishing a youth center is not enough without parental support. So, family involvement should be strengthened around the youthfriendly health services (35 years old male, key informant).

... it is necessary to strengthen the youth center and make all kinds of services accessible. For example, if an adolescent becomes pregnant at that adolescent's age, the family holds the girl in their home or that girl may get stuck in something unnecessary. So, I believe it would be good if the government could expand the coverage of youth services. (27 years old female, key informant).

\section{Subtheme: Involvement of Religious Leaders in SRH Services Provision}

Healthcare providers suggest that the involvement of religious leaders in SRH services is essential to develop acceptable community intervention and to improve the current SRH service in the way of religious acceptability, particularly related to safe abortion services.

In my opinion, these things (Safe abortion service) need to be discussed in-depth with the religious leaders. Discussion with religious leaders is essential because the healthcare providers easily accept what the religious leaders who come from his/her religious say. The religious leader may also give direction to the follower (healthcare providers). Therefore, health professionals and religious leaders should be able to discuss it. (37 years old male, key informant).

\section{Discussion}

The findings of this study reveal that social norms strongly influence healthcare provider perceptions towards the provision of sexual and reproductive health services. Most healthcare providers describe that, due to social norms associated with premarital sex, they do not give sexual and reproductive services for unmarried adolescents as required. They explain that social models in Ethiopia are strong; the adolescents may face different problems if they utilized sexual and reproductive health services. They also express that they counsel unmarried adolescents to abstain from sexual activity until marriage. The healthcare provider perceived that providing sexual and reproductive health services for unmarried adolescents means encouraging 
unmarried adolescents to engage in sexual activity before marriage. This finding is consistent with other findings in Ethiopia. $^{3,16}$ Similar to this study finding, the finding of a study conducted in DR Congo also shows stigma discouraged adolescents to access and utilized sexual and reproductive health services. ${ }^{25}$ Another qualitative study in Tanzanian found that adolescents discouraged seeking SRH services due to community stigma. ${ }^{26}$ Similar findings were also reported in a study conducted in Ibadan, Nigeria, where healthcare providers, instead of giving contraceptives for unmarried adolescents, preferred unmarried adolescents to abstain from sex until marriage. ${ }^{14}$ This might be due to the effect of a normatively driven protective role of healthcare providers which is exacerbated by the pervasive norms about sex and contraception being only for married women. One study also suggested that the healthcare provider perceived that they were seen as having an important role in protecting the spread of premarital sex in the community. ${ }^{27}$ This study finding implies that the protective role of the healthcare provider at health facilities is one of the great challenges for adolescents to access and utilize sexual and reproductive health services. It also suggests that community-based sexual and reproductive services seem to fail. So the current strategy should be revised by including key community members like religious leaders, community elders, parents, and teachers.

Healthcare providers in this study had ambivalent attitudes towards providing safe abortion and contraceptive services for unmarried adolescents due to their religious beliefs and cultural norms.

Religious beliefs are the ones that prevent healthcare providers from providing safe abortion services among the interviewed healthcare providers. Most of the interviewed healthcare providers refer the adolescents to the nearest health facility where abortion services are available. Similar to these study findings, the findings of the study conducted in Ibadan, Nigeria also show that healthcare providers had ambivalent attitudes towards providing contraceptives for adolescents due to their moral beliefs. ${ }^{14}$ However, the findings of a study conducted in Ghana among midwives show that their religious beliefs did not prevent them from providing abortion care because they perceived that doing safe abortion services is their professional duty and needed to help prevent deaths from unsafe abortion. ${ }^{28}$

Moreover, our study revealed that the healthcare providers were demotivated to provide SRH services for an unmarried adolescent when the adolescent repeatedly asked them for the same services. A qualitative study conducted in
Southwest, Ethiopia ${ }^{16}$ showed that most adolescents repeatedly asked for the same benefits due to lack of awareness, or it may be due to their peer influences. So, healthcare providers should give vital counseling to adolescents.

The findings of this study revealed that the healthcare providers were motivated to provide sexual and reproductive health services due to their previous experiences. They experienced that most adolescents in the study area become pregnant due to inadequate knowledge about sexual and reproductive health services. Some also experienced unintended pregnancy due to rape. This motivated healthcare providers to provide sexual and reproductive health services. A similar finding has been reported in the study conducted in Ghana. Midwives are motivated to provide services for adolescents because of their experiences of maternal death due to unsafe abortions. ${ }^{28}$ Another qualitative study finding conducted in South Africa also shows that nurses were motivated by their experiences as teenagers to serve SRH services to adolescents. ${ }^{4}$

In this study, the study participants put the most significant emphasis on healthcare systems-related barriers like a shortage of medical supplies and equipment like modern contraceptive methods, condoms, test kits (pregnancy and STI kit) which limits the provision of sexual and reproductive health services for unmarried adolescents. Studies conducted in southern Ethiopia and southwest Ethiopia also support this study finding. ${ }^{3,16}$ A qualitative study conducted in South Africa also shows that insufficient SRH skills and shortage of time to provide the necessary care hinder the provision of adequate SRH services to adolescents. ${ }^{4}$ This study finding implies that health system barrier further contributes to the unfriendliness of the services environment to access and utilization of sexual and reproductive health services by unmarried adolescents.

Lack of training about sexual and reproductive health services for adolescents limited the healthcare provider to provide quality healthcare services for adolescents. Study participants witness that, due to lack of training, most youth centers as well as health centers failed to meet adolescents' needs. The findings of this study support bythe empirical study conducted in Kenya, which shows that most service providers do not have adequate counseling skills and do not receive any special training on how to handle adolescents. ${ }^{23}$

\section{Conclusion}

The findings of this study show that the provision of sexual and reproductive health services seems, for 
unmarried adolescents, inadequate, due to the strong influence of social norms on health workers' perception towards the provision of sexual and reproductive health services. In addition, most healthcare providers had ambivalent attitudes towards providing safe abortion and contraceptive services for unmarried adolescents due to their personal religious beliefs. Moreover, the shortage of essential medical supplies and lack of training further limit the provision of sexual and reproductive health services. Adolescent resistant behavior and lack of parental support further complicated sexual and reproductive health services for unmarried adolescents. Therefore, an urgent response is needed from governmental and nongovernmental organization to save the life of adolescents. As the findings show that most of the barriers come out of the healthcare system, future studies should explore the role of social norms on the provision of sexual and reproductive health services for unmarried adolescents.

\section{Ethical Consideration}

Before the actual data collection, ethical approval was secured from Arba Minch College of Health Sciences research and ethical review directorate. After explaining the purpose of the study, permission to conduct this study was granted by the respective city administration health

offices and district health officers. Finally, written informed consent was obtained from each study participant after clearly describing the aim of the study. To keep confidentiality and anonymity we used a code to label the healthcare provider and their respective health facility. The study participants also agreed to publish their responses for better improvement of the Adolescent Health program. All recommended COVID-19 prevention measures were applied to protect the data. The suspected cases were linked with the nearby health facility COVID-19 task forces. Besides, this study was conducted following the Declaration of Helsinki, and all ethical and professional considerations were followed throughout the study to keep participants' data strictly confidential.

\section{Acknowledgments}

The research team would like to thank the School of Public Health, College of Medicine and Health Sciences, Wolaita Sodo University for giving the chance to develop this $\mathrm{PhD}$ dissertation. Also, we would like to thank Arba Minch Health Science College and PHARMA College for their support during the proposal development, and facilitating the logistics for the data collection. We would like to extend our gratitude to research assistants (Bilcha Oumer, Sultan Hussen, and Abdulselem Turke) who helped us during the data collection process and English language edition. Finally, we thank all study participants who gave their precious time to respond to our questions.

\section{Funding}

The authors received no financial support for the research, authorship, or publication of this article.

\section{Disclosure}

The authors declare no potential conflicts of interest for this work nor concerning the research, authorship, and publication of this article.

\section{References}

1. Waiswa P. Sexual and Reproductive Health for Young People in Africa: A Strong Government-Led Multisectoral Approach is Urgently Needed. Springer; 2020.

2. World Health Organization. Adolescent pregnancy fact sheet. January 2020. Available from: https://www.who.int/newsroom/fact-sheets /detail/adolescent-pregnancy. Accessed November 17, 2021.

3. Habtu Y, Kaba M, Mekonnen H. What do service providers in Southern Ethiopia think about barriers to using youth-friendly sexual and reproductive health services for adolescents?: Qualitative study. Reprod Health. 2021;18:1-15. doi:10.1186/s12978-021-01092-0

4. Jonas K, Crutzen R, Krumeich A, et al. Healthcare workers' beliefs, motivations and behaviours affecting adequate provision of sexual and reproductive healthcare services to adolescents in Cape Town, South Africa: a qualitative study. BMC Health Serv Res. 2018;18 (1):1-13. doi:10.1186/s12913-018-2917-0

5. Kabakian-Khasholian T, Quezada-Yamamoto H, Ali A, et al. Integration of sexual and reproductive health services in the provision of primary health care in the Arab States: status and a way forward. Sex Reprod Health Matters. 2020;28(2):1773693. doi:10.1080/ 26410397.2020.1773693

6. Mekonnen Munea A, Alene GD, Debelew GT. Does youth-friendly service intervention reduce risky sexual behavior in unmarried adolescents? A comparative study in West Gojjam Zone, Northwest Ethiopia. Risk Manag Healthc Policy. 2020;13:941-954. doi:10.2147/RMHP.S254685

7. Olika AK, Kitila SB, Terfa YB, et al. Contraceptive use among sexually active female adolescents in Ethiopia: trends and determinants from national demographic and health surveys. Reprod Health. 2021;18(1):1-11. doi:10.1186/s12978-021-01161-4

8. Shilton S, Chandra-Mouli V, Paul S, et al. Facilitators and barriers in the utilization of World Health Organization's preventing early pregnancy guidelines in formulating laws, policies and strategies: what do stakeholders in Ethiopia say? Int J Adolesc Med Health. 2019. doi:10.1515/ijamh-2019-0028

9. Federal Democratic Republic of Ethiopia Ministry of Health. National adolescent and youth health strategy (2016-2020); October 2016. Addis Ababa, Ethiopia.

10. George A, Jacobs T, Ved R, et al. Adolescent health in the sustainable development goal era: are we aligned for multisectoral action? BMJ Global Health. 2021;6(3):e004448. doi:10.1136/bmjgh-2020-004448

11. Ndayishimiye P, Dine RD, Dukuze A, et al., Perceptions and barriers toward sexual reproductive health services accessibility, availability and quality among adolescents in selected cities of Rwanda. 2020. 
12. Mutea L, Ontiri S, Kadiri F, et al. Access to information and use of adolescent sexual reproductive health services: qualitative exploration of barriers and facilitators in Kisumu and Kakamega, Kenya. PLoS One. 2020;15(11):e0241985. doi:10.1371/journal.pone.0241 985

13. Napit K, Shrestha KB, Magar SA, et al. Factors associated with utilization of adolescent-friendly services in Bhaktapur district, Nepal. J Health Popul Nutr. 2020;39(1):1-9. doi:10.1186/s41043020-0212-2

14. Ahanonu EL. Attitudes of healthcare providers towards providing contraceptives for unmarried adolescents in Ibadan, Nigeria. J Family Reprod Health. 2014;8(1):33.

15. Mulaudzi M, Dlamini BN, Coetzee J, et al. Perceptions of counsellors and youth-serving professionals about sexual and reproductive health services for adolescents in Soweto, South Africa. Reprod Health. 2018;15(1):1-9. doi:10.1186/s12978-018-0455-1

16. Hailemariam S, Gutema L, Agegnehu W, et al. Challenges faced by female out-of-school adolescents in accessing and utilizing sexual and reproductive health service: a qualitative exploratory study in Southwest, Ethiopia. J Prim Care Community Health. 2021;12: 21501327211018936. doi:10.1177/21501327211018936

17. Dapaah JM. Attitudes and behaviours of health workers and the use of HIV/AIDS health care services. Nurs Res Pract. 2016;2016:1-9. doi:10.1155/2016/5172497

18. Henok A, Takele E. Assessment of barriers to reproductive health service utilization among Bench Maji Zone Pastoralist Communities. Ethiop J Health Sci. 2017;27(5):523-530. doi:10.4314/ejhs.v27i5.11

19. Muntean N, Kereta W, Mitchell KR. Addressing the sexual and reproductive health needs of young people in Ethiopia: an analysis of the current situation. Afr J Reprod Health. 2015;19(3):87-99.

20. Devers KJ, Frankel RM. Study design in qualitative research-2: sampling and data collection strategies. Educ Health. 2000;13 (2):263. doi:10.1080/13576280050074543
21. O'reilly M, Parker N. 'Unsatisfactory saturation': a critical exploration of the notion of saturated sample sizes in qualitative research. Qual Res. 2013;13(2):190-197. doi:10.1177/1468794112446106

22. World Health Organization. Adolescent friendly health services for adolescents living with HIV: from theory to practice, December 2019: technical brief. World Health Organization; 2019.

23. Godia PM, Olenja JM, Lavussa JA, et al. Sexual reproductive health service provision to young people in Kenya; health service providers' experiences. BMC Health Serv Res. 2013;13(1):1-13. doi:10.1186/ 1472-6963-13-476

24. Rak KJ, Kuza CC, Ashcraft LE, et al. Identifying strategies for effective telemedicine use in intensive care units: the ConnECCT study protocol. Int J Qual Methods. 2017;16(1). doi:10.1177/ 1609406917733387

25. Muanda FM, Gahungu NP, Wood F, et al. Attitudes toward sexual and reproductive health among adolescents and young people in urban and rural DR Congo. Reprod Health. 2018;15(1):1-14. doi:10.1186/s12978-017-0439-6

26. Hokororo A, Kihunrwa AF, Kalluvya S, et al. Barriers to access reproductive health care for pregnant adolescent girls: a qualitative study in Tanzania. Acta paediatrica. 2015;104(12):1291-1297. doi:10.1111/apa.12886

27. Olivari MG, Cucci G, Confalonieri E. "Beyond personal beliefs" Italian health care providers' self-perception of their own job attitudes and reflections on the contraceptive behaviors of adolescent patients. Sage Open. 2016;6(4):2158244016672714. doi:10.1177/ 2158244016672714

28. Oppong-Darko P, Amponsa-Achiano K, Darj E. "I am ready and willing to provide the service ... though my religion frowns on abortion"-Ghanaian Midwives' mixed attitudes to abortion services: a qualitative study. Int $J$ Environ Res Public Health. 2017;14 (12):1501. doi:10.3390/ijerph14121501
Risk Management and Healthcare Policy

\section{Publish your work in this journal}

Risk Management and Healthcare Policy is an international, peerreviewed, open access journal focusing on all aspects of public health, policy, and preventative measures to promote good health and improve morbidity and mortality in the population. The journal welcomes submitted papers covering original research, basic science, clinical \& epidemiological studies, reviews and evaluations, guidelines, expert opinion and commentary, case reports and extended reports. The manuscript management system is completely online and includes a very quick and fair peer-review system, which is all easy to use. Visit http://www.dovepress.com/testimonials.php to read real quotes from published authors. 